International Journal of Business and Management Review

Vol.1, No.4, pp. 72-82, December 2013

Published by European Centre for Research Training and Development UK(www.eajournals.org)

\title{
THE ANALYSIS AND APPLICABILITY OF COGNITIVE THEORIES IN SOLVING INCONSISTENCY AMONG COGNITIVE ELEMENTS
}

\author{
Hart O. Awa, PhD \\ Sunday C. Eze, PhD
}

\begin{abstract}
This paper critically analyses the major theoretical and empirical body of knowledge of the various schools of thought of cognitive consistency with a view of proffering a tripartite approach (involving the consumers, the organizations and the government) to solving inconsistency among cognitive elements (e.g., values, beliefs, knowledge and attitudes). The Heider's balance theory, Osgood's congruity model and Festinger's cognitive dissonance theory were specifically looked into and assessed in terms of their real world application and/or empirical fertility. Each of these theorists emphasizes psychological tension and the urge to achieving consistency within and between the cognitive system and overt/covert behaviour.
\end{abstract}

KEYWORDS: Cognitive Theories, Consumers, Organizations, Government

\section{INTRODUCTION}

Research interest in social psychology shows an integral relationship between the three existential stances (knowing, feeling, and acting), which interrelate to form a richer and more flexible construct (McGuire, 1969). Sheth (1974) supports when he notes that the interaction between affect (the individual liking or disliking a stimulus), and behavioural intention (the tendency to respond, either favourably or unfavourably, towards the stimulus). Man comes to love what is familiar and the unfamiliar is always discomforting and disturbing though common knowledge tells us that what is unfamiliar turns familiar sooner or later (Vekatesan, 1973). The consistency theorist emphasize that affect (liking or disliking) is hypothesized to be a function of beliefs related to the perceived instrumentality of object or concept in attaining or frustrating a set of relevant valued states, weighted by the relative importance of those valued states (Osgood, Suci and Tannenbaum, 1957; Rosenburg, 1960; and Day, 1973). The theory of propositional control of Dunaley (1966) considers bahavioural intention to be a function of two factors. First, attitude towards a specific act defined in terms of beliefs about the consequences of performing that act, weighted by the evaluation of those beliefs; and second, social and personal normative beliefs, weighted by motivation to comply.

The phenomenon therefore is that man holds information or knowledge, which reflects his beliefs or evaluations about stimuli- objects, events, persons or environments. Such knowledge, opinions and beliefs about stimuli constitute his cognition. Day (1973) observes that consistency theorists share the basic assumption that individual strives to achieve consistency within and between his cognitive systems and his overt/covert behaviour. Thus, man seeks to maintain cognitive consistency irrespective of the circumstances. In addition, these theorists assume that inconsistency among cognitions creates psychological tension or discomfort(motivational state), which is disturbing in much the same way as any other drive state, such as thirst, and thus forces 
drive reduction action(s). The result tension is the motivational force leading to efforts to modify or change the cognitive system. The magnitude of psychology tension, according to Day (1973), could be considerable or appreciable in nature. The appreciable tension, which is most applicable to businesses, is the consequence of everyday problems, such as when favourite brand is out-of-stock or actual performance of an untried/new product falls short of the expected performance. The specific modes of resolution of these inconsistencies are of obvious concern to the relevant manufacturers and trade dealers. For instance, psychological tension aroused by shortfall in product performance may attract public or private actions and perhaps the ideals of attribution theory, to restore consistency. The public actions relate to seeking redress in the court of law, forming consumer movements, complaining to the offending organization for compensation or for more dissonance-reducing instruction or complaining to Public Complaints Commission or any other bodies in charge of handling consumer dissatisfaction(s).Private actions, on the other hand, involve boycotting the offending product and its maker, warning people known to him to beware and engaging in repression. Jones etal (1972) report that attribution theory explains how people assign the causality to events in terms of their own behaviour(especially success) or the behaviour of others(e.g.; dissonant issues). For instance, a student who failed examination may resolve that in terms of his/her perceived teacher's hatred.

McGuire(1966) discusses six ways by which inconsistency can be created in a man. First, inconsistency results from an individual's simultaneous occupation of two or more conflicting social roles. Informed decisions complement one's social roles because the time for the search and comparison efforts increasingly complete and conflict with job demands, leisure time and time for attending to other issues, thereby enforcing decisions that create inconsistencies. Linder(1970) predicts that the process of allocating decreasing personal time lead to increasing tension in a society. Second, environmental change may encumber an individual with issues that no longer accord with the reality of life as in the case of computer and typewriter, diskette and flash drive, etc. Third, an individual may be constrained to behave in ways inconsistent with his original attitudes, perhaps as a result of death of a dear one, loss of job, or some other pressing events. Fourth, an individual may be persuaded to change his belief structure via new information, interpersonal interactions or firsthand experience, only to find that, that may be inconsistent with other elements of the cognition (Day 1973). Fifth, individuals seek inconsistency, either because of a desire for change or novelty, or to mask more deep-seated conflicts that can rarely be resolved through action. Finally, there are human logical shortcomings that perhaps produce logical fallacies, though inconsistency theory is usually based on psycho-logic rather than formal logic.

The theorists of cognitive-consistency often record three most significant schools of thought- the Heider's balance theory (1946 and 1958), Osgood and Tannennenbaum's congruity theory (1955), and Festinger's cognitive dissonance theory (1957). The fundamental thrust of these theories is the tendency to enforce a reduction of a state of disequilibrium among one's cognitions. While the balance theorists seek to cause balance relations among cognitions perhaps were imbalanced; congruity theorists strive to turn incongruity among attitudes to consistency; and dissonance theorists are preoccupied with reducing dissonant cognitions. Although some modifications have taken place on the formulations of the postulates of these schools, Deustch (1968) notes that they tend to draw their philosophical and theoretical bases from many of the 
Published by European Centre for Research Training and Development UK(www.eajournals.org) aspects of the field theory framework of Lewin. This paper attempts to synthesize the submissions of these three major schools and the improvements thereon with a view to drawing antecedent conditions and modes of inconsistency reduction in consumption related bahaviour.

\section{Balance Theory}

The balance theory as pioneered by Heider (1946) and (1958) is preoccupied with structural property of cognitive elements, involving a perceiver or a person, $\mathrm{P}$, who perhaps simultaneously exhibits negative or positive cognition relations with an object, $\mathrm{X}$, and some other person, $\mathrm{O}$. Its basic thrust is that individuals subconsciously alter cognitive elements in such a manner to re-orientate balance, consistency or harmony (Schiffman and Kanuk, 1987; and Day, 1973). P has cognition about $\mathrm{O}$ and $\mathrm{X}$, and he is interested in O's cognition about X (Venkatesan, 1973), which reflects a triangular relationship.

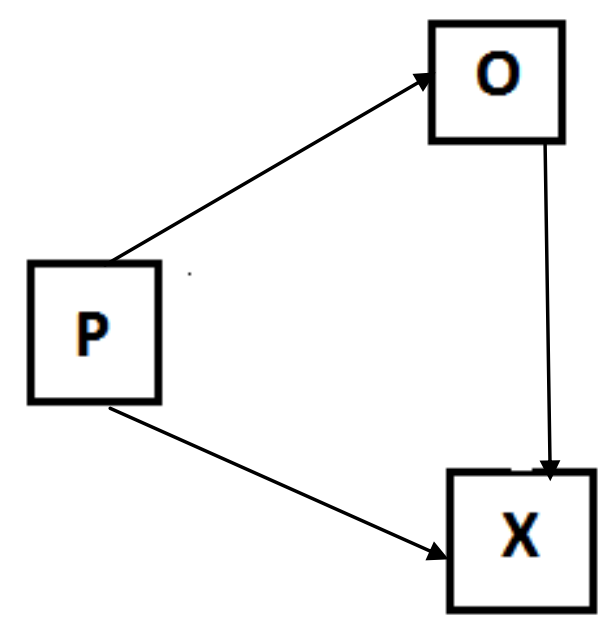

Figure 1: Relations of P-X-O triad

To illustrate the relations of P-X-O triad, let us consider two brothers, James and John, their attitudinal relations to Star lager beer, and James attitude towards John or vice versa. Initially, James had negative cognition about Star beer, but John, a renowned professional brewer recommends it for its excellence mixture of ingredients. This recommendation from proven source is capable of causing James to change his negative attitude towards Star lager beer. The reverse would had been the case if John had recommended otherwise, perhaps projecting Gulder lager as the best when James had negative disposition to Gulder. Thus, P likes or dislikes objects, $\mathrm{X}$ or $\mathrm{O}, \mathrm{O}$ like or dislikes $\mathrm{X}$, etc. The psychological state is plausibly one of three-balance, imbalance and non-balance (Newcomb, 1968). It is balanced when the set of cognitive elements is accepted as it is. Relations in the P-O-X triad are considered balance when all three relations are positive, or when the algebraic product of the three signs is positive (Day 1973) or when actual performance equals expectation. Abelson and Rosenberg (1960) opine that balanced outcome is enthroned when the tendencies toward hedonic gain and consistency operate in same direction. When non-balanced, indifference possibly exists between acceptance and modification is feasible or when the resulting algebraic product of the relationship among the triad is negative. The balance theorists assert that balanced states are most preferable to imbalanced states, and imbalanced relations instigate action(s) to modify the cognitive set to install balance though the 
modes of doing that were out rightly ignored by the early theorists. Thus, balanced states are assumed stable and to resist change whereas, imbalanced states change so as to enthrone balance. However, the early postulates have been accused of being seemingly parochial in identifying and dealing with states of balance and imbalance relations.

The starting point of many newer and perhaps refined theories, rest upon four snags of the early theorists (Kiesler, Collins and Miller, 1969). First, the theory lacks route guides on the modes of obtaining balanced states. Second, it lacks provision for degree of balance or imbalance, or intensity of the relations desired by a person. Third, the theory rarely copes with complex situations involving multiple relations within triad, or the inclusion of other persons or objects. Last, the liking or disliking relations is assumed ambiguous, vague and lacks specifics. Zajonc(1960) observes that no matter how much John likes James; it may be difficult to influence John to like Star lager beer, though according to the balance theory James should influence John perhaps with his experience(s). Against Heider's postulates, Jacoby(1970) reports from his survey that negatively valence sources stating dislike for novel consumer item(s) will generate increase in preference rates, and perhaps intent to buy. On this platform, Cartwright and Harry(1956) sought to refine, formalize, extent or complement Heider's concept of cognitive balance by covering more than tradic relationships though Zajonc(1968) attacks them for having a mathematical treatment that did not conform to empiricism. Abelson and Rosenberg's (1958) cognitive balancing model and Abelson and Rosenberg (1960) represent an extensive modification of Heider's theory with much greater complementary extension. These experts postulate a single affective relationship between psychological objects, which may be favourable, unfavourable or null; and devised a number of alternative ways to restore balance. According to them, the probability of using a particular method is inversely proportional to the amount of psychological effort required by the method. Day (1973) reviews their works and opines that the least effortful method is operationally defined as requiring the fewest sign changes before balance is restored. So, the recognition of Heider's balance theory of the need to turn to person(s) assists to resolve cognitive imbalances with a minimal effort. Individuals prefer solutions that maximize hedonic gain, which operates independent of the striving for consistency; they try to maximize potential gain and maximise potential loss (Abelson and Rosenberg, 1960). Although this model is classic and represents an improvement upon the basic model, Day (1973) accuses of having an unimpressive empirical support and problem of how hedonic gain and hedonic loss could be measured.

On this basis, he strongly advises that the conceptual frameworks of the general balance theory could be beefed up by incorporating some of the strengths of the well-developed concepts of perceived risk by Bauer(1960) and Cox(1967). By this theory, what determines the shape of P's cognitive elements towards $\mathrm{X}$ and $\mathrm{O}$ is the extent of $\mathrm{P}^{\prime} \mathrm{s}$ involvement in the decision(s). Involvement theorists posit that individual's decisions and/or action is affected, among others, by the amount of capital outlay, information search efforts and risk level, frequency of behaviour and expressiveness of the decisions' outcomes. If the perceived risk is high(that is, high involvement behaviour), $\mathrm{P}$ relies perhaps not only on $\mathrm{O}_{1}$ to ensure balanced cognition but also on $\mathrm{O}_{2}, \mathrm{O}_{3} \ldots \mathrm{O}_{\mathrm{n}}$ to improve or change his cognition in other to enhance satisfaction from $\mathrm{X}_{1}$ or even change to $\mathrm{X}_{2}, \mathrm{X}_{3} \ldots \mathrm{X}_{\mathrm{n}}$. This is same as complex behaviour, where a decision-maker seeks balanced relations by being conscious and aggressive in information search leading to 
Published by European Centre for Research Training and Development UK(www.eajournals.org) satisfactory evaluation and informed decision.

Conversely, if the perceived risk is low (that is, low involvement behaviour). $\mathrm{P}$ relies less on $\mathrm{O}_{1}$, $\mathrm{O}_{2}, \mathrm{O}_{3} \ldots \mathrm{O}_{\mathrm{n}}$ to ensure balanced cognition, rather he shuns repeat behaviour towards $\mathrm{X}_{1}$ if satisfaction is less than expectations and perhaps favors $X_{2}, X_{3}, X_{4} \ldots X_{n}$. The explanation to this is that $\mathrm{X}_{1}, \mathrm{X}_{2}, \mathrm{X}_{3} \ldots \mathrm{X}_{\mathrm{n}}$ are less risky and take low capital outlay, less expressive, frequently done, and convenient decisions. The hierachy of effects for the low-and-high involvement behaviours is shown below in Figure 2.

\section{High Involvement Behaviour}

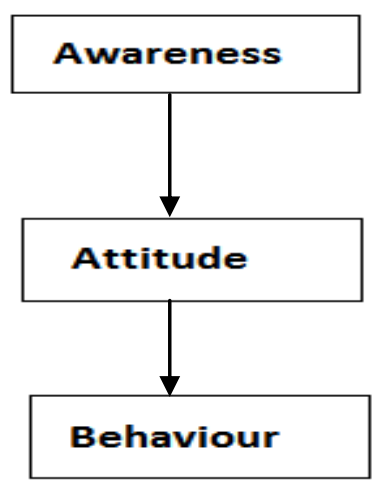

\section{High Involvement Behaviour}

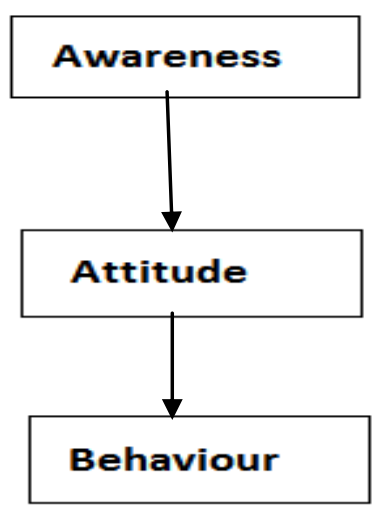

Figure 2: Hierachy of effects of low-and-high-involvement behaviours.

Sheth (1969) observes that friends and relatives might willingly dispose unsolicited advice on low-risk decisions than on high-risk ones, because any adverse consequences may not likely stain the established rapport.

\section{Congruity Theory}

Osgood's congruity model (Osgood, Suci and Tannenbaum, 1957; Osgood, 1960; and Tannenbaum, 1967) represents a second major consistency formulation though at variance with the balance theory as Day (1973) notes that it handles the problem of communication effects. The theory of a person $(\mathrm{P})$ receiving favourable assertions from an identifiable source $(\mathrm{S})$ about an object, event or other person $(\mathrm{O})$, which informs his (P's) attitude formation or change. The congruity principle has the kudos of attempting to specify precisely the direction of change; either to $\mathrm{O}$ or $\mathrm{S}$. S makes some assertions about $\mathrm{O}$ and the pressure is to change only the existing attitudes for or against $\mathrm{S}$ or $\mathrm{O}$. The extent of influence of $\mathrm{S}$ on $\mathrm{P}$ 's attitude depends, to a very great extent, upon how much $\mathrm{P}$ likes or dislikes $\mathrm{S}$ and $\mathrm{O}$, as well as the enormity of the message. Of course, this special model, which often measures attitudes with reasonable precisions via the use of Semantic Differential Scale, yields precise predictions. First is that if $\mathrm{P}$ likes $\mathrm{S}$ and $\mathrm{O}$ prior to the information from $S$, and the assertion is favourable, then there will be congruity. Second is when incongruity prevails (i.e.; $\mathrm{P}$ likes both $\mathrm{S}$ and $\mathrm{O}$, whereupon $\mathrm{S}$ relays negative information about $\mathrm{O}$ to $\mathrm{P}$ ), $\mathrm{P}$ 's attitudes toward both $\mathrm{S}$ and $\mathrm{O}$ changes and ultimately forcing $\mathrm{P}$ to the direction of wanting to re-introduce congruity. Incongruous states generate a pressure for change in 
attitudes toward S and/or O (Venktesan, 1973) and the amount of attitude change required of P to deal with the situation is inversely proportional to the initial intensity of the attitude(Day, 1973). Osgood (1960) opines that extreme attitudes ignite the least amount of change.

However, the theory has gathered empirical supports from social psychology and consumer behaviour. Day notes that the theory has done well in its limited domain (1973). Very limited empirical works can be found to test the theory's general implications and none for novelty seeking (Venkatesan, 1973), and generalization beyond the restricted type of communications situation is rather thorny (Tannenbaum, 1968). Robertson's (1970) has shown that congruity principle has done reasonably well in acceptance or endorsement of new products. For instance, a disliked celebrity used to endorse a product may contaminate it (the product). Consider a situation where a consumer has a balanced cognition towards food products and a favourable attitude towards General Food Company and its coffee brand (+) and an unfavourable attitude towards new coffee products, which he perceives inferior alternatives (-). General Foods then introduces Maxim Freeze-dried coffee, stressing its superiority (+). Under these conditions, attitudinal imbalance is obvious and change is most likely to occur. The possible outcomes of these may be as follows. $\mathrm{P}$ has favourable attitude towards $\mathrm{S}$ (brand) perhaps because $\mathrm{S}$ (the manufacturer) conveyed positive assertion about $\mathrm{S}$ (brand). $\mathrm{P}$ has already a set of dispositions towards $\mathrm{S}$ (product class) and $\mathrm{S}$ (manufacturer). Thus if $\mathrm{P}$ has a positive cognition towards $\mathrm{S}$ (the new coffee), congruous state is aroused, whereas if he had negative cognition towards the product category, positive assertion by $S$ (manufacturer) may cause him to seek the new coffee version. But if $\mathrm{P}$ had negative cognition towards $\mathrm{S}$, even if his attitude towards the product category is positive, novelty will rarely be sought or aroused.

\section{Cognitive-Dissonance Theory}

The theory of cognitive dissonance posits a human phenomenon used by psychologists to express psychological difficulties (Altschul and Sinclair, 1981) or a state of disequilibrium amongst one's cognition (values, beliefs, attitudes and knowlegde) resulting from the inflow of conflicting messages, objects, events or experiences. Whereas the balance theory is concerned with interpersonal perception; the congruity theory deals with attitude change resulting from conveyance of information from a source about an object, event, or person; the theory of cognitive dissonance seems to have wider applications and empirical fertility than the others and enjoys practical fascination to both the social psychologists and consumer behaviour scientists. The social psychologists have been motivated by controversies to enrich theory, while the consumer behaviour scientists have been attracted by the theory's flexibility and unique insights into post-purchase behaviour.

According to Festinger (1957) and his followers, relations exist between relevant cognitions of man. Any two or more cognitive elements (e.g.; values, attitudes, beliefs knowledge) may be consonant, dissonant or irrelevant to one another. Assuming we de-emphasize the issuse of relevance and score all beliefs or attributes as relevant, then a satisfactory relationship between cognitive elements is characterized by fitting or consonant relationship. A psychological tension result from non-fitting of or contradiction amongst, cognitive elements connotes dissonance relations. The magnitude of dissonance experienced and the probability of action depends on the situation. Festinger notes that dissonance is likely to be high when either of the following 
International Journal of Business and Management Review

Vol.1, No.4, pp. 72-82, December 2013

Published by European Centre for Research Training and Development UK(www.eajournals.org)

happens.

- There is a mistake in high involvement decision(s); decisions that are expressive, infrequent, involve high capital outlay and requires aggressive search effort to reduce perceived risk. Such decisions are rarely revocable once taken or revocable at a very heavy loss to the decision-maker.

- The alternatives are quantitatively dissimilar (Nnedu, 1996) or there is little cognitive overlap or sharing of features (Day, 1973). For instance, a choice between a car and an aeroplane creates a more dissonance relation than a choice between a Mercedes Benz and KIA.

- The desirable alternatives are perhaps enormous and the choice results from freewill effort or outside-applied pressure. If pressure is applied, the decision-maker complies without letting his cognition challenged (Festinger and Carlsmith, 1959).

\section{The Strategies for Resolving Cognitive Inconsistency}

The concept of cognitive consistency is built around the theory of hedonism. The theory posits man to be a calculative and pleasure seeking animal that chooses alternative courses of action that are capable of giving him the maximum satisfaction or pay-off. It also follows Thorndike's law of effects, which emphasizes that behaviour that yields positive outcomes will be reinforced or repeated. Festinger (1964) reports that inconsistency arousal and effort to reduce/eliminate it and ultimately return to fit or consonance takes place only after decision; thus, consequences flow from the decision. Inconsistency creates psychological tension and anxiety, and therefore the organism is aroused to finding ways to reduce or remove it. When tuned to consumption related decisions, Ukoh(1993) reports that handling inconsistent relations involves a tripartite activity, involving the consumers, the organisations and the governments, though studies have shown that consumer interest is weakest in public policy perhaps because they are not well organized. Perhaps, the organization of Nigerian consumers is almost not more than a mob, which is at variance with Ralph Nader's philosophy about consumer movement. For individuals/consumers, Atlschul and Sinclair (1981) break the modes of resolution into problem-focused and emotion-focused, though they note that the latter is predominantly used. The former operates when the individual thinks he can change the inconsistent relations in his favour. The modes of doing things, among others, include exercising carefulness and impartiality in gathering and evaluating information (Venketesan, 1973) leading to decision; revoking the inconsistent behaviour (e.g.; selling out the product in question, dashing it out, throwing it away or returning it to the seller, especially when the seller stimulates repeat behaviour via liberal return policy); and changing cognition to increase cognitive overlap or to psychologically decrease the attractiveness of the rejected alternative(s) and increase the attractiveness of the chosen. The latter exists when anything is rarely done to the inconsistent relations and as such, the individual resorts to strategies that allow him to cope or live with ugly situation. Among others, the modes include seeking out advertisement(s) or information that supports the choice while voiding inconsistent-creating stimuli/information, down-rating the relevance attached to the discrepant areas or re-evaluating the conflicting beliefs to create fit or consonant; or by engaging in repression, defense mechanisms and rationalization.

In liaison with the organization, the influx of predatory and cut-throat competition in almost all the industries, which Hoskin, Macve and Stone (1997) note followed the rapid pace of technological innovation and increasing customer sophistication, encourages players to formulate policies that enforce a consonant-creating environment. The policies that reflect on that, among 
International Journal of Business and Management Review

Vol.1, No.4, pp. 72-82, December 2013

Published by European Centre for Research Training and Development UK(www.eajournals.org)

others, include the following.

- Quality improvement on attributes and features such as functionality, versatility, durability, serviceability, dexterity etc.; need to be constant to show superiority over customer expectation and those of competitors. Favourable experience improves routinized behaviour, repeat behaviour and advocacy.

- Advertising messages should underscore the unique selling points presented as, Nnedu (1996) posits in a factual, logical and careful manners that will enhance consistency among the consumer's cognitive elements.

- Messages should be clear, definite, persuasive and truthful before, during and after behaviour to ensure informed decisions and dissonance-free exchanges. Where necessary, performance should be under-stated in advertising messages to encourage satisfaction or over-satisfaction and of course congruous relations. Further, promotion should emphasize existing and satisfied users to reassure and congratulate them for making wise choice decision.

- Provision of after-sale service (such as free transportation and installation, instruction booklets, etc.) and developing effective mechanism for handling customer complaints to ensure effective but consonant performance that promises the flow of advocacy.

Finally, governments in the course of governance owe it a duty to regulate business operations and to protect the general public's interests, since everybody is a customer, perhaps through direct participation and/or creation of regulatory institutions and agencies. Recently, the government of China demonstrated this duty by banning the importation of meats from seven American states for containing hazardous residues. In Nigeria, several agencies and institutions have been to prevent the exploitative tendencies of organizations, or inconsistent relations arousal on citizenry, though the effectiveness of most of them is in doubt owing to bureaucratic red-tapism, policy inconsistency, power change, poor funding, workers' insincerity, lack of transparency in governance, and a host of other factors. Some of these agencies and institutions are National Agency for Food and Drug Administration Control (NAFDAC), Standard Organization of Nigeria (SON), Public Complaints Commission (PCC), Nigeria Drug Law Enforcement Agency (NDLEA), Federal and State Environmental Protection Agencies and Nigeria Enterprise Promotion (NEP). Most of these, if not all, have performed below expectations and therefore creating room for pertinent questions to beg for analysis by Nigerian government and business scholars and practitioners. How many dissatisfied consumers have been compensated through the efforts of Public Complaints Commission? Why it is that many medicated soaps made in Nigeria still contain excess mercury? Why are many product claims exaggerated even with the existence of SON, NAFDAC and perhaps APCON? Why do we continue to experience drug trafficking and consumption of inimical goods as well as the sale of non-treated bottled and sachet water when NAFDAC and NDLEA are in existence? Granted that NAFDAC has fared better than before with its present boss, Professor Nora Akunyili but much is still needed to reposition it via giving people and organizations re-orientations geared at internalization of, and exhibition of behaviour that reflects on, socially and economically acceptable norms. This will reflect positively on cognitive consistency of Nigerian consumers. However, when all agencies and institutions are almost inefficient as they are in Nigeria, dissatisfied consumers will be left with private actions (e.g.; boycotting the products and warning others to beware) rather than public actions (e.g.; confrontation, redress in court, complaining to 
International Journal of Business and Management Review

Vol.1, No.4, pp. 72-82, December 2013

Published by European Centre for Research Training and Development UK(www.eajournals.org)

PCC, etc.), which is the case in advanced economies.

\section{Conclusions}

The quest for models that provide better description and understanding of multi-faceted attribute structures has been proceeding along two tracks. One track has its roots to consistency theory and requires highly structured judgments about specific attributes. The other, though incorporates preference judgments into a perceptual space, is based on multi-dimensional scaling techniques, which make fewer demands of respondents. The two extremes are converging as hybrid methods that extract the strengths of each (Johnson, 1971) to form a richer construct. The reviews of literature on cognitive consistency theory takes a provocative stride and advocated relationships with Thorndike's law of effects and the theories of hedonism, conceptual conflicts, economic man, novelty seeking and rationality though Berlyne (1963) views total consistency unpleasant when he notes that man seeks inconsistency and consistency to an optimal level. The provocative stride is explained on the grounds that attitude change results directly from one's experience and/or from the immediate problems of another, referred to as the communicator of word-of-mouth. Bauer (1964) observes overlap when audience exerts considerable initiative in interpreting and using the incoming persuasive messages for its own purpose. Thus, perceptual conflicts are motivating to attract consistent relations. Man presumably and impartially collects and evaluates information about available alternatives in order to make informed or inconsistent-free decisions. This precondition exercise is an integral part of the cognitive process, and thus, once decision is made, psychological situation changes decisively, either negatively or positively. Venkatesan (1973) concludes less objectivity, partiality and bias now characterized the process. Actual behaviour turns what seemed novel at the pre-decision stage into a familiar case as its pros and cons have been evaluated, and the individual is now disposed to express the extent of consistency or inconsistency existing among the elements of his cognition - beliefs, values, knowledge and attitudes.

Of the three schools of thought (balance, congruity and dissonance), the postulates of the last have wider practical fascination and empirical fertility than the other two perhaps because the direction of and the modes of resolving inconsistent relations are embedded in theory simple deals with interpersonal perception $(\mathrm{P}-\mathrm{X}-\mathrm{O})$ triad; the congruity theory relates to how attitude change results from source's message about an object, event, or person; and the cognitive dissonance theory, in addition to handling the direction of the inconsistent relations like Osgood's(1960) congruity model, treats the strategies for returning the psychological tension to consistent relations. Thus, each latter postulate represents an improvement upon the immediate former. Inconsistency is a cognitive but post-behaviour phenomenon aroused when there is an inflow of stimuli that conflicts with one's cognition about an object, oneself, one's action and/or environment. Operationally, individuals experience inconsistency when they hurriedly make a novel decision without the usual search efforts; when there is a negative relationship between actual and expected behaviours, etc. Often consumers cognitively form performance expectation about a choice through mass media and word-of-mouth (Bass, 1969). The quest to reduce the concomitant psychological tension and anxiety often reflects on the level of risk involved in the decision; for high risk decisions, the quest is aggressive, perhaps because they are infrequent, expressive and command high capital outlay. However, inconsistency comes from myriad of sources and as such dealing with it will involve the tripartite of consumers, organizations and 
International Journal of Business and Management Review

Vol.1, No.4, pp. 72-82, December 2013

Published by European Centre for Research Training and Development UK(www.eajournals.org)

government.

\section{REFERENCES}

Abelson, R. \& Rosenberg, J. (1960) Symbolic psycho-Logic: A Model of Attitudinal Cognition. Behavioural Science, 3. Pp. 1-13

Altschul, A. \& Sinclair, H. (1981) Psychology for Nurses $5^{\text {th }}$ ed. The English Language Book Society and Bailliere Tindell, London.

Bauer, R.(1960). Consumer Behaviour as Risk Taking. In Dynamics Marketing for a Changing World. Hancock, R. (ed.). American Marketing Association, Chicago.

Bass, F.(1969). A New Product Growth Model for Consumer Durables Management Sciences 15(Jan.), Pp.215-227

Berlyne, D. (1960) Conflict,Arousal and Curiousity. McGraw-Hill Company, New York

Cartwright, D. Harary, F. (1956).Structural Balance:A Generalization of Heider's Theory. Psychological Review, PP277-93

Cox, D. (1967). Risk Taking and Information Handling. In Consumer Behaviour. Cox,D.(ed.). Graduate School of Business Administration,Havard University, Boston

Day, G.(1973).Theories of Attitude Structure and Change. In Consumer Behaviour: Theoretical Sources. Ward, S. \& Robertson, T.(eds.) Prentice-Hall, Inc; Englewood Cliffs, New Jersey

Deustch, M.(1986) Field Theory in Social Psychology. In Handbook of Social Psychology. Lindzey, G \& Aaronson,E. (eds.). Reading, Mass: Addison-Wesley Publishing Co; Inc. Pp.412-87

Dulaney, D.(1968). Awareness, Rules and Proporsitional Control: A Confrontation with S-R Behaviour Theory. In Verbal Behaviour and General Behaviour

Therapy. Dixon, T. \& Horton, D.(ed.) Prentice-Hall Inc., Englewood Cliffs. Festinger,L.(1957). A Theory of Cognitive Dissonance. Stanford University Press,Stanford.

Festinger,L.(1964). Conflict,Decision and Dissonance Stanford University Press,Stanford.

Festinger, L. \& Carlsmith, J.(1959) Cognitive Consequences of Forced Compliance. Journal of Abnormal and Social Psychology, 58. PP203-10.

Hoskin, K, Macve, R. \& Stone,J.(1997). The Historical of Modern Business and Military Strategy:1850-1950. Interdisciplinary Perspectives on Accounting

Conference,Manchester,7-9,July. PP19-46

Heider, F. (1946). Attitude and Cognitive Organization. Journal of Psychology,21,PP107-12

Heider, F.(1958). The Psychology of Interpersonal Relations. John Wiley\&Sons, NY

Jacoby, J.(1970). Exploring the potential of Negative sources. An Application of Heider's Balance Model. Paper No 110, Purdue Papers on Consumer Psychology. In Day,G.(1973). Theories of Attitude Structure and Change. In Consumer Behaviour: Theoretical Sources. Ward, S.\&Robertson,T.(eds.). PrenticeHall, Inc,Englewood Cliffs.

Johnson,R.(1971). Market Segmentation: A Strategic Management Tool. Journal of Marketing Research,8(Feb.)PP13-9.

Jones,R.; Linder,D; Kiesler,C.; Zanna,M.\&Brehm,J.(1972) Internal States or External Stimuli Observers'Attitude Judgements and the Dissonance Theory - Self-Persuasion Controversy. Journal of Experimental Social Psychology,4 PP247-69

Kiesler,C; Collins, B;\& Miller,N.(1969). Attitude Change: A Critical Analysis of Theoretical 
Published by European Centre for Research Training and Development UK(www.eajournals.org)

Approches. John Wiley\&Sons,Inc; NY

Linder,S.(1970). The Harried Leisure Class. Columbia University Press, NY

Mc.Guire,W.(1969). The Nature of Attitude and Attitude Change. In Handbook of Social Psychology, Vol. 111( $2^{\text {nd }}$ ed.) Lindzey, G.\& Aronson,E.(eds)Addison-Wesley Publisher Co; Inc;Reading, Mass.

Newcomb, T.(1968). Interpersonal Balance. In Theory of Cognitive Consistency: A Sourcebook. Abelson,R\&Others, and McNally\&Co.Skokie, 111

Nnedu, E.(1996).Business Policy and Startegic Management: Theory and Practice. Paragraphics, Port Harcourt.

Osgood,C;\&Tannenbaum,P.(1955).The Principles of Congruity in the Prediction of Attitude Change. Psychologu Review.62 PP42-45

Osgood,C(1960). Cognitive Dynamics in the conduct of Human Affairs. Public Opinion Quarterly.24 PP341-65

Osgood,C.; Suci,G.;\& Tannenbaum,P.(1957). The Measurement of meaning. University of Illinois Press,Urbana, 111.

Robertson,T.(1970). Consumer Behaviour. Scott, Foreman\&Co.;Glenview, 111

Rosenberg,M.\&Abelson,R.(1960). An Analysis of Cognitive Balancing. In Attitude Organization and Change. Rosenberg,M. et. al(eds.) Yale University Press New Heaven,Conn.

Schiffman,L.\&Kanuk,L.(1987). Consumer Behaviour $3^{\text {rd }}$ ed. PrenticeHall International,Inc; Englewood Cliffs, New Jersey

Sheth,J.(1974). A Field of Study Attitude Structure and the Attitude Behaviour Relationship. In Models of Buyer Behaviour: Conceptual, Quantitative and Empirical. Sheth,J.(ed.) Harper\&Row Publishers, NY

Sheth,J.(1969). Attitude as a Function of Evaluative Belief. A Paper Presented at the American Marketing Association Workshop on Consumer Behaviour, Columbus, Ohio. August(a)

Tannenbaum,P.(1968). The Congruity Principles: Retrospective Reflection and Recent Research. In Theories of Congnitive Consistency: A Sourcebook. Abelson,R. \&Others(eds.) Rand McNally\&Co.; Skokie, 111

Ukoh,J(1993). Monograph on Consumer Behaviour. Dept of Management Studies, University of Calabar, Calabar.

Zajonc,R.(1968). Cognitive Theories in Social Psychology. In Handbook of Social Psychology. Lindzey,G.\&Aronson,E.(eds.). Addison Wesley Publishing Co.; Reading, Mass.

Zajonc,R,(1960). The Concept of Balance, Congruity and Dissonance. Public Opinion Quarterly. 24. PP280-96

Venkatesan,M.(1973). Cognitive Consistency and Novelty Seeking. In Consumer Behaviour: Theoretical Sources. Ward,S.\&Robertson,T.(eds.).Prentice- Hall,Inc;Englewood Cliffs, New Jersey 